\title{
Video Article \\ Quantitative Measurement of GLUT4 Translocation to the Plasma Membrane by Flow Cytometry
}

\author{
Shyny Koshy ${ }^{1}$, Parema Alizadeh ${ }^{1}$, Lubov T. Timchenko ${ }^{1}$, Christine Beeton ${ }^{1}$ \\ ${ }^{1}$ Department of Molecular Physiology and Biophysics, Baylor College of Medicine \\ Correspondence to: Christine Beeton at beeton@bcm.edu \\ URL: https://www.jove.com/video/2429 \\ DOI: doi:10.3791/2429
}

Keywords: Cellular Biology, Issue 45, Glucose, FACS, Plasma Membrane, Insulin Receptor, myoblast, myocyte, adipocyte

Date Published: $11 / 7 / 2010$

Citation: Koshy, S., Alizadeh, P., Timchenko, L.T., Beeton, C. Quantitative Measurement of GLUT4 Translocation to the Plasma Membrane by Flow Cytometry. J. Vis. Exp. (45), e2429, doi:10.3791/2429 (2010).

\section{Abstract}

Glucose is the main source of energy for the body, requiring constant regulation of its blood concentration. Insulin release by the pancreas induces glucose uptake by insulin-sensitive tissues, most notably the brain, skeletal muscle, and adipocytes. Patients suffering from type-2 diabetes and/or obesity often develop insulin resistance and are unable to control their glucose homeostasis. New insights into the mechanisms of insulin resistance may provide new treatment strategies for type-2 diabetes.

The GLUT family of glucose transporters consists of thirteen members distributed on different tissues throughout the body ${ }^{1}$. Glucose transporter type 4 (GLUT4) is the major transporter that mediates glucose uptake by insulin sensitive tissues, such as the skeletal muscle. Upon binding of insulin to its receptor, vesicles containing GLUT4 translocate from the cytoplasm to the plasma membrane, inducing glucose uptake. Reduced GLUT4 translocation is one of the causes of insulin resistance in type-2 diabetes ${ }^{2,3}$.

The translocation of GLUT4 from the cytoplasm to the plasma membrane can be visualized by immunocytochemistry, using fluorophoreconjugated GLUT4-specific antibodies.

Here, we describe a technique to quantify total amounts of GLUT4 translocation to the plasma membrane of cells during a chosen duration, using flow cytometry. This protocol is rapid (less than 4 hours, including incubation with insulin) and allows the analysis of as few as 3,000 cells or as many as 1 million cells per condition in a single experiment. It relies on anti-GLUT4 antibodies directed to an external epitope of the transporter that bind to it as soon as it is exposed to the extracellular medium after translocation to the plasma membrane.

\section{Video Link}

The video component of this article can be found at https://www.jove.com/video/2429/

\section{Protocol}

\section{Cell Staining}

1. Prepare the cells. The cells should be used while still actively growing (60-80\% confluence). Serum starve the cells overnight, plate them cells at 0.1 million per well in $0.5 \mathrm{~mL}$ serum-free medium in a 24 -well plate and place in the incubator $\left(37^{\circ} \mathrm{C}, 5 \% \mathrm{CO}_{2}\right)$ for 30 min -2 hours to recover from trypsinization.

2. Mix the primary and secondary antibodies. Mix ( $5 \mu \mathrm{L}$ of primary anti-GLUT4 antibody with $1 \mu \mathrm{L}$ secondary chicken anti-goat IgG antibody conjugated to AlexaFluor 488) x number of wells. Incubate for 10 minutes at room temperature, in the dark.

3. Prepare a $2 X$ working stock of insulin by diluting it in medium.

4. Check if the cells have adhered or not.

5. Gently add $6 \mu \mathrm{L}$ antibody mix and $0.5 \mathrm{~mL}$ of your $2 \mathrm{X}$ working stock of insulin to the wells containing the cells. Avoid any turbulence of the medium. Incubate $\left(37^{\circ} \mathrm{C}, 5 \% \mathrm{CO}_{2}\right)$ for 30 minutes, in the dark.

6. Fix the cells by adding $0.5 \mathrm{~mL}$ of PBS $+1 \%$ PFA to each well, without shaking the cells. Incubate for 20 minutes at room temperature, in the dark.

7. If your cells have adhered to the wells, gently lift them with a cell lifter. Transfer the cells ( $1 \mathrm{~mL}$ total) into tubes that fit in your flow cytometer and centrifuge to pellet the cells.

8. Wash the pellet twice with $1 \mathrm{~mL}$ PBS and resuspend in $0.4 \mathrm{~mL}$ PBS $+1 \%$ PFA. At this point, cells can be wrapped in foil and stored in the fridge $\left(4-8^{\circ} \mathrm{C}\right)$ or taken to the flow cytometer for immediate data acquisition. 


\section{Data Acquisition}

1. Set a broad gate around the live cells in the side scatter (SSC) versus forward scatter (FCS) panel. Use a negative tube (cells not treated with insulin or cells "stained" with an isotype control) to set your FL1 parameter. Make sure your peak is completely in the panel, not cut on the lower side.

2. Acquire data from at least 10,000 cells per tube.

\section{Data Analysis}

1. Draw a gate around the live cells in the SSC vs FSC panel (Figure $1 \mathrm{~A}$ ). Plot the histograms of AlexaFluor 488 fluorescence intensity versus number of cells within the live-cell gate (Figure 1B). You can overlay different histograms to visualize differences but for quantitation, determine the mean and median fluorescence intensity for each cell population and use these numbers for your comparisons (Figure 1C).

2. Normalize the data to the value obtained in the absence of insulin, as shown in Figures $1 \mathrm{C}$ and 1D.

\section{Representative Results}

In myoblasts isolated from a healthy individual (no insulin resistance), insulin induces a dose-dependent translocation of GLUT4 from the cytoplasm to the plasma membrane (Figure 1, left). In contrast, insulin does not induce GLUT4 translocation to the plasma membrane of myoblasts isolated from a patient with insulin resistance (Figure 1, right).

Control

No insulin resistance

A

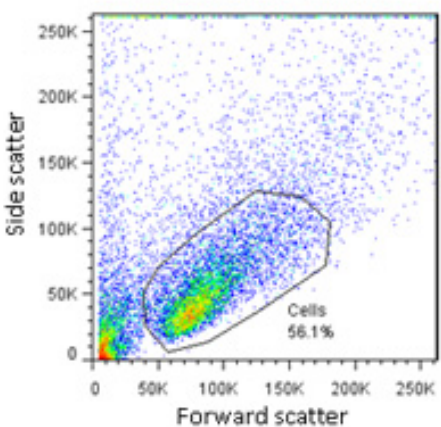

B

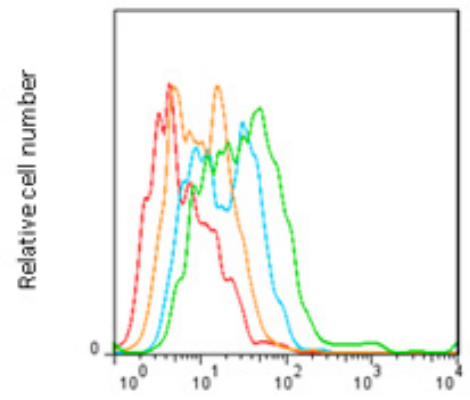

Alexafluor 488 staining intensity

\begin{tabular}{|c|c|c|}
\hline Cells treatment & MFI & $\begin{array}{c}\text { Normalized } \\
\text { MFI }\end{array}$ \\
\hline No insulin & 10 & 1.0 \\
\hline $1 \mathrm{nM}$ insulin & 15 & 1.5 \\
\hline $10 \mathrm{nM}$ insulin & 67 & 6.7 \\
\hline $100 \mathrm{nM}$ insulin & 101 & 10.1 \\
\hline
\end{tabular}

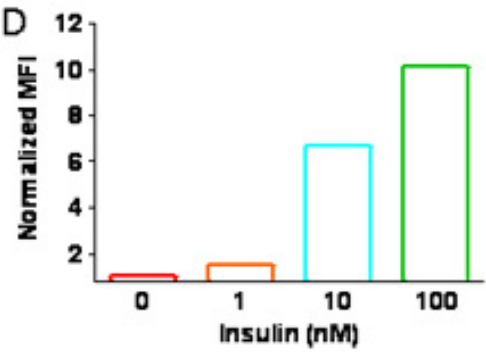

Patient with insulin resistance
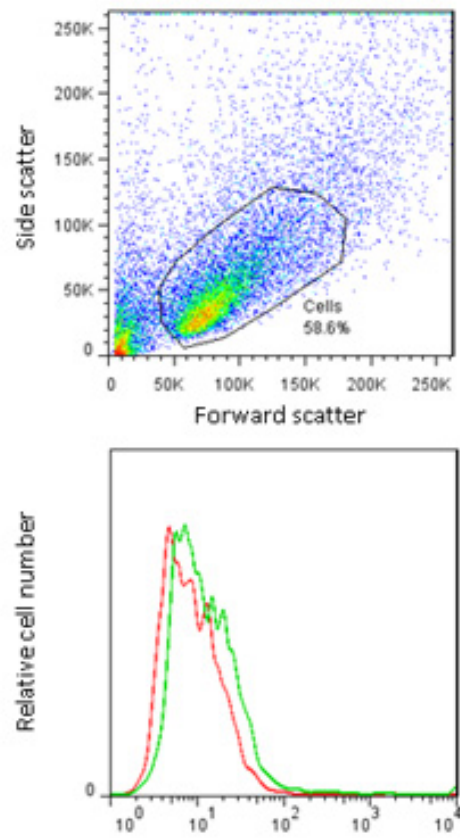

Alexafluor 488 staining intensity

\begin{tabular}{|c|c|c|}
\hline Cells treatment & MFI & $\begin{array}{c}\text { Normalized } \\
\text { MFI }\end{array}$ \\
\hline No insulin & 16 & 1.0 \\
\hline 1 nM insulin & 14 & 0.9 \\
\hline $10 \mathrm{nM}$ insulin & 19 & 1.2 \\
\hline $100 \mathrm{nM}$ insulin & 21 & 1.3 \\
\hline
\end{tabular}

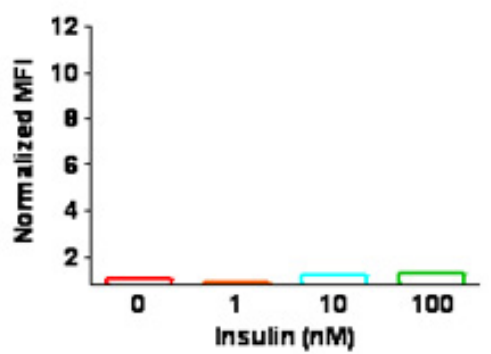


Figure 1. Example of a staining experiment. Myoblasts were isolated from a donor without insulin resistance (left) and from a patient with insulin resistance (right). A, SSC (side scatter) versus FCS (forward scatter) plot with a gate around the live cells. B, Cells gated in A, stained with the antibody against an external epitope of GLUT4, and left unstimulated (red) or stimulated with insulin $1 \mathrm{nM}$ (blue), $10 \mathrm{nM}$ (orange), or 100 $\mathrm{nM}$ (green). For figure clarity, we only show data without and with $100 \mathrm{nM}$ insulin for the cells with insulin resistance. C, Mean fluorescence intensities (MFI) of the histograms shown in B were normalized to the MFI of the cells left unstimulated (no insulin). D, Plots of the normalized MFI data from the histograms shown in B.

\section{Discussion}

We have demonstrated a rapid technique for quantifying the translocation of GLUT4 from the cytoplasm to the plasma membrane of cells by flow cytometry.

GLUT4 is only transiently expressed at the plasma membrane of cells and is endocytosed. Since the bound antibodies remain attached to the GLUT4, even during endocytosis, the fluorescence signal gives the total amount of GLUT4 that was exposed at the plasma membrane during the chosen duration of incubation in the presence of insulin.

This technique can also be applied to studying the translocation of other proteins from an intracellular compartment to the plasma membrane, provided a good antibody directed to an external epitope of the protein of interest is available. For example, a similar assay is now commonly used to assess the rate of degranulation of cytotoxic T lymphocytes and natural killer lymphocytes by measuring the translocation of CD107a to their plasma membrane $e^{4,5}$. The translocation of phosphatidylserine from the inner side of the plasma membrane to the outer side during cell apoptosis or necrosis can also be detected by flow cytometry, using fluorophore-labeled Annexin $\mathrm{V}^{6}$.

Besides rapidity of the assay, flow cytometry presents the advantage of allowing the study of protein translocation to the plasma membrane in mixed cell populations. Indeed, one can combine staining for cell subset markers and for the protein of interest, followed by data acquisition on a multi-laser flow cytometer ${ }^{7}$.

The amounts of antibodies given in paragraph 1.2 of the protocol are a starting point; we recommend you titrate your antibodies with your cells of interest to determine the minimum antibody concentration that gives you a maximum signal. A good starting range for the primary anti-human GLUT4 antibody we have used here would be 1-10 $\mu \mathrm{L}$ per tube (i.e. $0.2-2 \mu \mathrm{g}$ antibody per tube), each tube containing no more than $1 \mathrm{million}$ cells. For other primary antibodies, refer to the supplier's instructions.

Normalization of data is necessary as autofluorescence of cells will vary from donor to donor and from experiment to experiment.

\section{Disclosures}

No conflicts of interest declared.

\section{Acknowledgements}

This work was supported by grants from the Mrs. Clifford Elder White Graham Endowed Research Fund \& the NIH (AR059838) to CB, from the NIH (AR052791, AR044387-ARRA, \& NS063298) to LTT, and by the Baylor College of Medicine Cytometry and Cell Sorting Core with funding from the NIH (NCRR S10RR024574, NIAID AI036211, \& NCI P30CA125123). The content is solely the responsibility of the authors and does not necessarily represent the official views of the $\mathrm{NIH}$.

\section{References}

1. Zhao, F.Q. \& Keating, A.F. Functional properties and genomics of glucose transporters. Curr. Genomics 8, 113-128 (2007)

2. Karnieli, E. \& Armoni, M. Transcriptional regulation of the insulin-responsive glucose transporter GLUT4 gene: from physiology to pathology. Am. J. Endocrinol. Metab. 295, E38-45 (2008).

3. Graham, T.E. \& Kahn, B.B. Tissue-specific alterations of glucose transport and molecular mechanisms of intertissue communication in obesity and type 2 diabetes. Horm. Metab. Res. 39, 717-721 (2007)

4. Betts, M. R., Brenchley, J. M., Price, D. A., De Rosa, S. C., Douek, D. C., Roederer, M. \& Koup, R. A. Sensitive and viable identification of antigen-specific CD8+ T cells by a flow cytometric assay for degranulation. J. Immunol. Methods 281, 65-78 (2003).

5. Alter, G., Malenfant, J.M. \& Altfeld, M. CD107a as a functional marker for the identification of natural killer cell activity. J. Immunol. Methods 294, 15-22 (2004).

6. Vermes, I., Haanen, C., Steffens-Nakken, H. \& Reutellingsperger, C. A novel assay for apoptosis. Flow cytometric detection of phosphatidylserine expression on early apoptotic cells using fluorescein labeled Annexin V. J. Immunol. Methods 184, 39-51 (1995).

7. Lugli, E., Roederer, M. \& Cossarizza, A. Data analysis in flow cytometry: the future just started. Cytometry A. 77A, 705-713 (2010). 